\title{
Electrodeposition of Pt - Rare Earth Alloys as ORR Catalysts for Fuel Cells
}

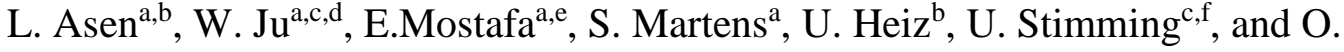 \\ Schneider ${ }^{\mathrm{a}}$ \\ ${ }^{\text {a }}$ Electrochemical Research Group, Institute of Informatics VI, Technical University of \\ Munich, 85748 Garching, Germany \\ ${ }^{\mathrm{b}}$ Chair of Physical Chemistry, Chemistry Department, Technical University of Munich, \\ 85748 Garching, Germany \\ ${ }^{c}$ Physics Department, Technical University of Munich, 85748 Garching, Germany \\ d current address: Materials for Energy Conversion, EMPA, Swiss Federal Laboratories \\ for Materials Science and Technology, 8600 Dübendorf, Switzerland \\ e permanent address: Chemistry Department, Faculty of Science, Mansoura University, \\ 35516 Mansoura, Egypt \\ ${ }^{\mathrm{f}}$ School of Chemistry, Newcastle University, Newcastle upon Tyne, NE1 7RU, United \\ Kingdom
}

Electrochemical deposition was studied as a potentially scalable method for the preparation of Pt-rare earth alloys for application as cathode catalyst in proton exchange membrane fuel cells. For this purpose, experiments both on electrodeposition of platinum and of the rare earth elements yttrium and lanthanum were carried out in two different types of ionic liquid. While the electrodeposition of platinum was successful in both liquids, the deposition of the rare earth metals was more challenging. The deposition of $\mathrm{Y}$ in a TFSI based liquid was prevented by electrode passivation, while in a $\mathrm{BF}_{4}{ }^{-}$liquid no passivation was seen, but also no clear indication of a deposition process was seen. For La, there was deposition using different precursors, but only at very low deposition rates. The nature of the deposit could not yet be unequivocally determined. Initial attempts in alloy deposition were not successful.

\section{Introduction}

Hydrogen fuel cell driven electric vehicles have been released for commercial sale (1), but the efficiency of the fuel cells is still far below the thermodynamic limit. The high amount of Pt catalyst therefore required to deliver the power needed leads to costs too high for widespread market introduction (2). Especially overpotentials of several hundred $\mathrm{mV}$ at the cathode side due to the sluggish kinetics of the oxygen reduction reaction (ORR) are responsible for these drawbacks (3-5).

Catalytic materials with higher activity for the ORR and enhanced durability as well as reduced $\mathrm{Pt}$ loading can both bring down the costs and enhance the efficiency and therefore the competitiveness of fuel cell driven vehicles. Recently it has been shown that polycrystalline Platinum - rare-earth metal (RE) alloys show very promising catalytic properties for ORR, e.g. an increase in the kinetic current density by a factor of 3-5 compared to pure Pt $(2,6,7)$. They were reported to show a good stability due to their 
high heat of formation and the formation of a dense Pt overlayer during the initial dealloying steps (2). The overlayer is under compressive strain, causing the high activity (2, 7). Also for Pt-RE nanoparticles prepared in a cluster source, an enhanced mass activity was found (8).

For applying these alloys in actual fuel cells, the major challenge is to synthesize such nanoparticles with a method, which can be up-scaled to provide enough material for MEA fabrication and subsequently for widespread production for practical applications. This is challenging due to the very low standard potentials of the rare earth elements.

In this study electrochemical deposition was selected as a scalable method. However, due to the low deposition potential of rare-earth metals, aqueous electrolytes were not considered for these experiments. Therefore, other electrolytes, especially ionic liquids, were chosen as electrolyte, because they offer a wide electrochemical window (9) and in literature a successful deposition of selected pure rare-earth metals had been claimed (1016). For La-deposition, a peak potential of $-2.4 \mathrm{~V}$ vs $\mathrm{Fc}^{+} / \mathrm{Fc}$ was reported (12). However, there are also reports showing fundamental obstacles for deposition of RE metals from some ionic liquids (17). For example it was reported for (BMP)TFSI that the ions $\operatorname{Pr}^{2+}$ and $\mathrm{Nd}^{2+}$ were not stable and disproportionated, followed by a reaction of the metallic species with the ionic liquid (17). Therefore, in an additional approach organic solvents with an added supporting electrolyte were evaluated, which have also a wide potential window and where high amounts of precursors can be dissolved. These results are not shown.

The electrochemical deposition of Pt from ionic liquids has been reported as well (18, 19). Da Zhang et al. showed that in the ionic liquid N,N-diethyl-N-methyl-N-(2methoxyethyl)ammonium tetrafluoroborate $\left(\left(\mathrm{N}_{122,2 \mathrm{O} 1}\right) \mathrm{BF}_{4}\right)$ the four electron reaction of $\left[\mathrm{PtCl}_{6}\right]^{2-}$ occurs in two well separated steps, opposite to aqueous solutions (18). They studied the deposits formed on glassy carbon at two different potentials using scanning electron microscopy and transmission electron microscopy.

In this work, for every electrolyte system, the processes in solutions containing $\mathrm{Pt}$ precursors, rare earth metal ions or mixtures of both for alloy deposition were separately studied by the use of electrochemical techniques, mainly cyclic voltammetry and potentiostatic transients. Those were in part combined with the electrochemical quartz crystal microbalance (EQCM) technique, and ex-situ and in-situ scanning probe microscopy techniques as well as electrocatalytic measurements for the ORR. Aside from the gold electrode of the EQCM, highly oriented pyrolytic carbon was used as substrate material. Both $\mathrm{Pt}$ and rare earth deposition were studied in the same ionic liquids as an actual alloy deposition needs to be done from a mixed $\mathrm{Pt}$ - rare earth ion electrolyte. The ionic liquids selected were 1-octyl-1-methylpyrrolidinium bis(trifluoromethylsulfonyl)imide ((OcMePy)TFSI) and N,N-diethyl-N-methyl-N-(2methoxyethyl)ammonium tetrafluoroborate $\left(\left(\mathrm{N}_{122,2 \mathrm{O}}\right) \mathrm{BF}_{4}\right)$, motivated by the literature $(10,18)$. 


\section{Experimental Section}

In this work, two ionic liquids (ILs), 1-octyl-1-methylpyrrolidinium bis(trifluoromethylsulfonyl)imide ((OcMePy)TFSI) and N,N-diethyl-N-methyl-N-(2methoxyethyl)ammonium tetrafluoroborate $\left(\left(\mathrm{N}_{122,2 \mathrm{O} 1}\right) \mathrm{BF}_{4}\right)$, were used as solvent (IOLITEC). The purchased ILs were pretreated to remove residual oxygen and water before transfer into the glovebox by heating under vacuum. After pretreatment, both ILs were transferred into a glovebox (MBraun) with water and oxygen contents $<0.6 \mathrm{ppm}$. Different types of electrochemical cells were used for the experiments.

Electrochemical measurements on highly oriented pyrolytic graphite (HOPG, Mikromasch, grade ZYD) electrodes in both ILs were measured in a small threeelectrode cell without addition of a precursor. The HOPG electrode was freshly prepared before the experiments by cleaving the surface with an adhesive tape. Different potentiostats (Autolab PGSTAT30, Ivium Compact Stat Plus) were used. EQCMMeasurements were carried out in a special cell manufactured from Teflon. In these measurements, $10 \mathrm{MHZ}$ AT cut quartz crystals (KVG) were attached at the bottom of the cell. One of the $\mathrm{Au}$ electrodes of the quartz served as the working electrode (electrochemically active geometric area of $0.29 \mathrm{~cm}^{2}$ and piezoelectric active area of 0.19 $\mathrm{cm}^{2}$ ). In parallel to the electrochemical measurements, the electric admittance between the two circular Au electrodes on the quartz was measured in the vicinity of the resonance frequency using an Agilent E5100A Network analyzer. The saved admittance data were then fitted to a Lorentzian peak function using an automatic fitting routine, and the resonance frequency and the damping (full width at half maximum) were extracted from these data. In all measurements, Pt wires were used as counter and quasi-reference electrodes. Cyclic voltammetry (CV) and current transient measurements at different potentials were the main electrochemical techniques.

For Pt electrodeposition, electrolytes were prepared from $\mathrm{H}_{2} \mathrm{PtCl}_{6} \cdot 6 \mathrm{H}_{2} \mathrm{O}(99.995 \%$, Sigma-Aldrich) dissolved into the respective ionic liquid. As $\mathrm{H}_{2} \mathrm{PtCl}_{6}$ is unstable at high temperatures, an additional heat treatment up to $100{ }^{\circ} \mathrm{C}$ to remove water was not possible. Water traces from this precursor therefore could not be avoided. Characterisation of aqueous electrochemistry of the formed deposits was performed in standard electrochemical glass cells that had been cleaned in a mixture of sulfuric acid and hydrogen peroxide, followed by repeated boiling in ultrapure water. All solutions were prepared with ultrapure water from a Milli-Q system and high purity chemicals. Solutions were deaerated with Ar for voltammetric measurements, and saturated with oxygen gas for ORR activity measurements.

For Y electrodeposition, precursor electrolytes were prepared by adding $\mathrm{Y}\left(\mathrm{NO}_{3}\right)_{3} \cdot 6 \mathrm{H}_{2} \mathrm{O}$ into a few $\mathrm{ml}$ of the respective ionic liquid. The solution was heated to $110{ }^{\circ} \mathrm{C}$ for $24 \mathrm{~h}$ to remove the water, which was introduced by the hydrate. For $\mathrm{La}$ electrodeposition, $\mathrm{La}\left(\mathrm{NO}_{3}\right)_{3} \cdot 6 \mathrm{H}_{2} \mathrm{O}$ and $\mathrm{La}(\mathrm{TFSI})_{3}$ were used.

AFM measurements were carried out ex-situ in the tapping mode using a Veeco Nanoscope V instrument. 


\section{Results and Discussion}

\section{$\underline{\text { Pt electrodeposition from Ionic Liquids }}$}

The CV of HOPG was measured in $13.2 \mathrm{mM} \mathrm{H}_{2} \mathrm{PtCl}_{6}+$ (OcMePy)TFSI (Pt(OcMePy)TFSI) shown in Figure 1. The current of double-layer charging was much larger in the CV of HOPG in Pt-(OcMePy)TFSI than that in pure (OcMePy)TFSI (shown as inset), which is possibly contributed by the water or chloride traces in the solution influencing the solid-liquid interface. In the CV of HOPG in Pt-(OcMePy)TFSI, four peaks, two in the cathodic scan (peak a and b) and two in the anodic scan (peak c and d) in the potential range of $-2 \mathrm{~V}-0 \mathrm{~V}$, are clearly observed different to the profile obtained in the pure (OcMePy)TFSI. The four peaks are considered to be the redox peaks of $\mathrm{Pt}^{4+} /$ $\mathrm{Pt}^{2+}$ and $\mathrm{Pt}^{2+} / \mathrm{Pt}^{0}$. The deposition of $\mathrm{Pt}$ in ionic liquid through a multi-step procedure has been discussed by some authors $(18,19)$. Unlike the direct reduction of $\mathrm{Pt}^{4+}$ to $\mathrm{Pt}^{0}$ in aqueous solution, the $\mathrm{Pt}^{4+}$ in ionic liquid is reduced to $\mathrm{Pt}^{2+}$ first, and then to $\mathrm{Pt}^{0}$. In Figure 1a, peak a (at $-0.90 \mathrm{~V})$ and $\mathrm{b}($ at $-1.45 \mathrm{~V})$ indicate the reductions of $\left[\mathrm{PtCl}_{6}\right]^{2-}$ to $\left[\mathrm{PtCl}_{4}\right]^{2-}$ and $\left[\mathrm{PtCl}_{4}\right]^{2-}$ to metallic $\mathrm{Pt}$, respectively. Peak c (at $\left.-1.07 \mathrm{~V}\right)$ and $\mathrm{d}(-0.40 \mathrm{~V})$ are related to the oxidation of $\mathrm{Pt}^{0}$ to $\mathrm{Pt}^{2+}$ and $\mathrm{Pt}^{2+}$ to $\mathrm{Pt}^{4+}$. Therefore the observations in this work for (OcMePy)TFSI are similar to those in other ionic liquids, even though the potentials are different (however the Pt wire quasi-reference electrode scale cannot be easily compared between different liquids).

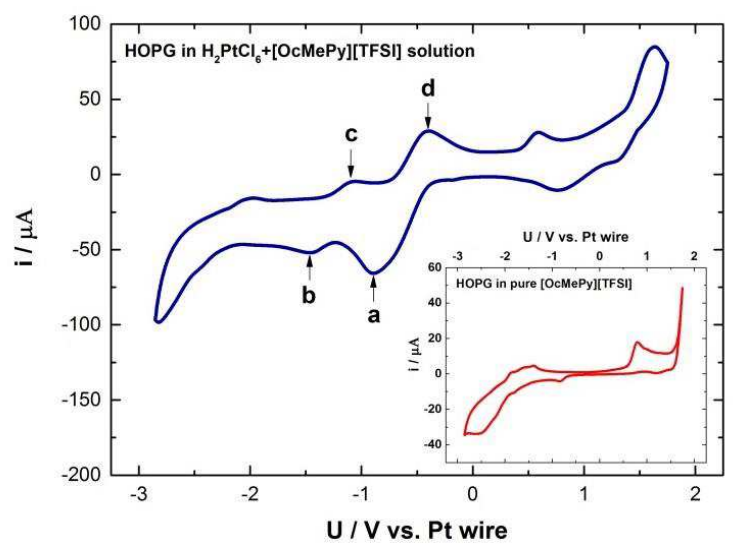

a)

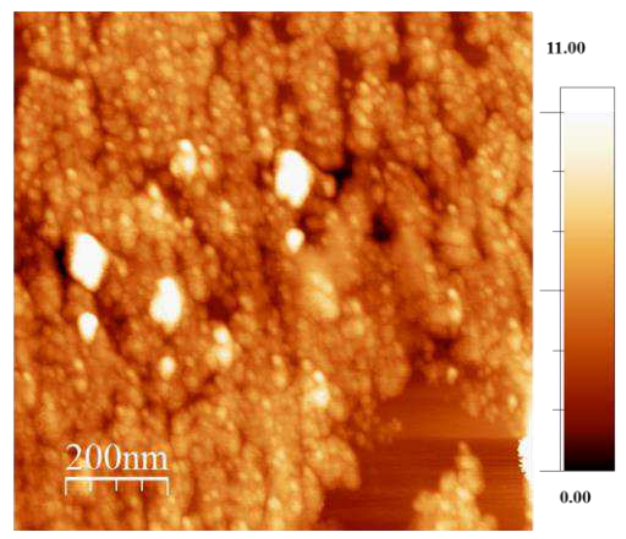

b)

Figure 1. a) The CV of HOPG in Pt-(OcMePy)TFSI and in pure (OcMePy)TFSI (inset). The peaks a and $d$ correspond to the redox couple $\mathrm{Pt}^{4+} / \mathrm{Pt}^{2+}$. The peaks $\mathrm{b}$ and $\mathrm{c}$ are related to the redox couple $\mathrm{Pt}^{2+} / \mathrm{Pt}^{0}$. Scan rate: $50 \mathrm{mV} / \mathrm{s}$. b) The morphology of $\mathrm{Pt} / \mathrm{HOPG}$ monitored by TM-AFM in atmosphere (z-scale: $11 \mathrm{~nm}$ ).

Repeated potential steps from $-0.2 \mathrm{~V}(5 \mathrm{~s})$ to $-1.5 \mathrm{~V}(5 \mathrm{~s})$ and back for 100 repeats were applied to a fresh HOPG working electrode to deposit Pt particles onto the surface. The open circuit potential (OCP) of HOPG in Pt-(OcMePy)TFSI was at $-0.2 \mathrm{~V}$. In the deposition procedure, the working electrode was kept at OCP for $5 \mathrm{~s}$ in each period in order to complement the $\mathrm{Pt}^{4+}$ ions by diffusion. The peak potential for $\mathrm{Pt}$ deposition in $\mathrm{Pt}-$ (OcMePy)TFSI is equal or higher than $-1.45 \mathrm{~V}$, which has been discussed above. Thus, an applied potential of $-1.5 \mathrm{~V}$ for Pt deposition was negative enough. The morphology of $\mathrm{Pt} / \mathrm{HOPG}$ from Pt-(OcMePy)TFSI was monitored by tapping mode atomic force microscope (TM-AFM) (Veeco Multimode) in air as shown in Figure 1b. Pt clusters are densely distributed on the HOPG surface with an average height of $\sim 4 \mathrm{~nm}$. In between, 
the smooth HOPG surface can be observed. The electrochemical properties of the Pt decorated $\mathrm{HOPG}\left(\mathrm{Pt} / \mathrm{HOPG}\right.$ ) surface was studied in $0.1 \mathrm{M} \mathrm{H}_{2} \mathrm{SO}_{4}$ by $\mathrm{CV}$ and by catalytic activity studies for ORR. Before the electrochemical measurements, the sample was cleaned stepwise in isopropanol, ethanol and deionized water to remove residual ionic liquid. The $\mathrm{CV}$ of $\mathrm{Pt} / \mathrm{HOPG}$ is shown in Figure 2a, which is a typical CV of Pt in sulfuric acid with peaks of Pt oxidation/ reduction and hydrogen ab-/ desorption. The active area of deposited $\mathrm{Pt}$ was determined with the transferred charge of Pt monoxide reduction. The catalytic activity of $\mathrm{Pt} / \mathrm{HOPG}$ for ORR (shown in Figure $2 \mathrm{~b}$ ) was measured in oxygen-saturated $0.1 \mathrm{M} \mathrm{H}_{2} \mathrm{SO}_{4}$ at different scan rates. The onset potential of ORR at $\mathrm{Pt} / \mathrm{HOPG}$ is at $\sim 0.85 \mathrm{~V}$ vs. SHE. The current density increases at first exponentially, until mass transport limitation of oxygen sets in. The shape of the sweep is similar to that of a one electron transfer reaction with a very slow reaction rate. It indicates that the deposited Pt performs poorly for ORR catalysis, which has a bottleneck at the ratedetermining step (RDS) of oxygen adsorption/ hydroxide desorption.

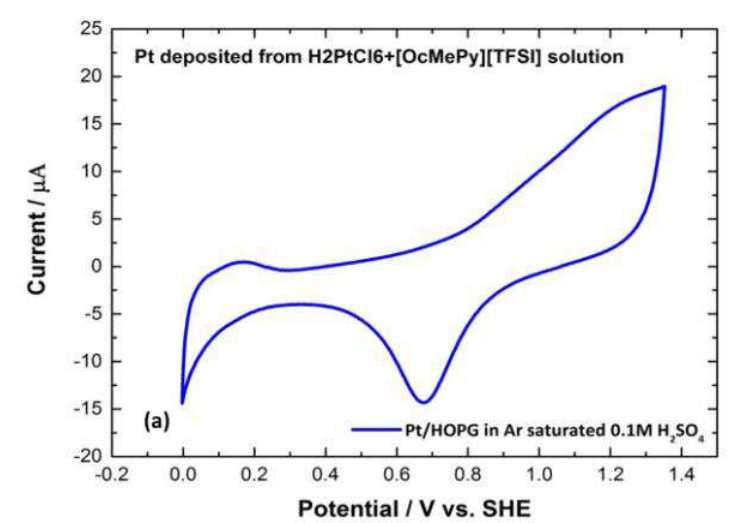

a)

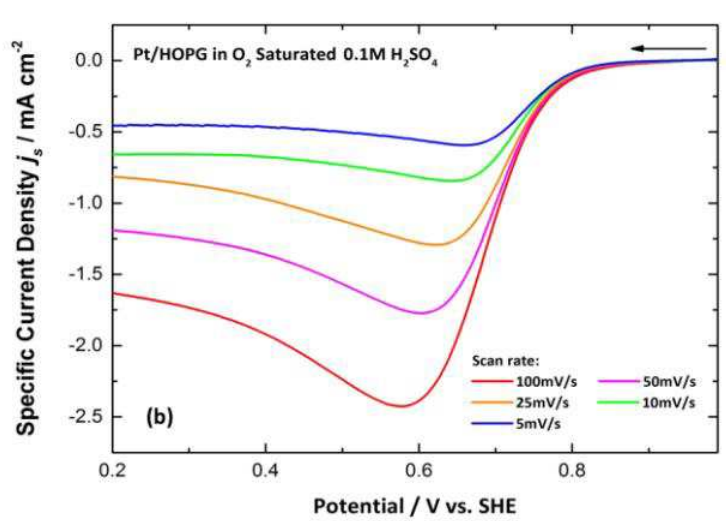

b)

Figure 2. The $\mathrm{CV}$ of $\mathrm{Pt} / \mathrm{HOPG}$ in Ar saturated $0.1 \mathrm{M} \mathrm{H}_{2} \mathrm{SO}_{4}$ at a scan rate of $50 \mathrm{mV} / \mathrm{s}$ (a) and the voltammetry of Pt/HOPG in ORR in oxygen saturated $0.1 \mathrm{M} \mathrm{H}_{2} \mathrm{SO}_{4}$ at different scan rates (b). The current in (b) was normalized to the active area of Pt, which was obtained from the transferred charge of Pt monoxide reduction.

Qualitatively similar results were also obtained for the electrodeposition of Pt from $\left(\mathrm{N}_{122,201}\right) \mathrm{BF}_{4}$. The electrodeposition of $\mathrm{Pt}$ from this ionic liquid has been discussed in literature (18) and is not shown here. Both ionic liquids selected in these studies permitted the electrodeposition of platinum nanoparticles, and are therefore suitable candidates for the alloy co-deposition.

\section{$\underline{\text { Y electrochemistry in ionic liquids }}$}

Y electrodeposition was attempted from both ionic liquids using yttrium nitrate as the precursor. In (OcMePy)TFSI a single pronounced reduction peak was seen in the voltammograms that however disappeared in subsequent cycles. All experiments indicated that initial reduction of the $\mathrm{Y}^{3+}$ ion resulted in a passivation reaction. In $\left(\mathrm{N}_{122,2 \mathrm{O})}\right) \mathrm{BF}_{4}$, however, the results were more promising. 


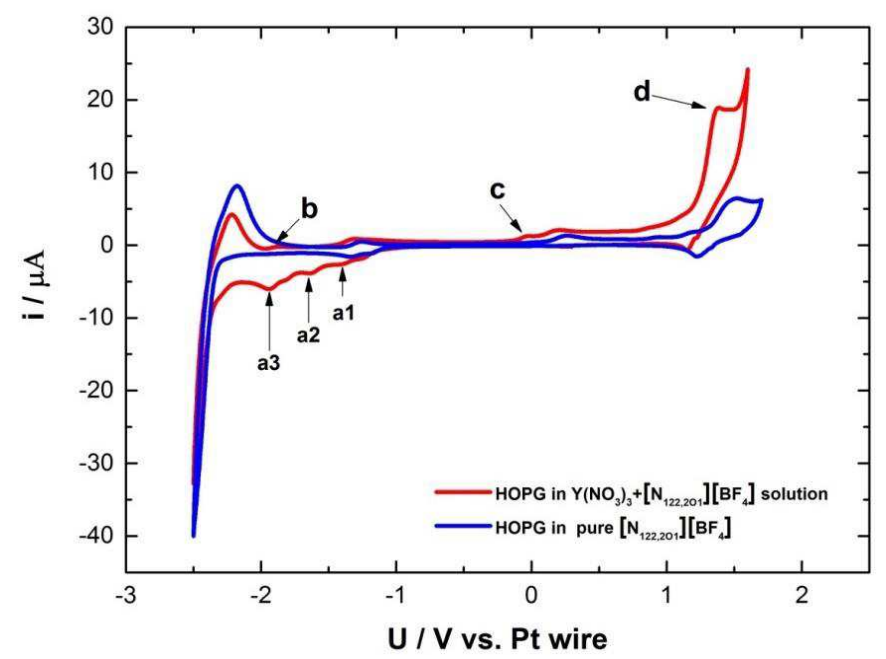

Figure 3. CVs of $\mathrm{HOPG}$ in pure $\left(\mathrm{N}_{122,2 \mathrm{O}}\right) \mathrm{BF}_{4}$ and in saturated $\mathrm{Y}\left(\mathrm{NO}_{3}\right)_{3}+\left(\mathrm{N}_{122,2 \mathrm{O}}\right) \mathrm{BF}_{4}$ solution (labelled curve). The reduction and oxidation peaks related to $\mathrm{Y}$ are labelled as $\mathrm{a} 1, \mathrm{a} 2, \mathrm{a} 3$ and $\mathrm{b}$.

The $\mathrm{CV}$ of HOPG in $\mathrm{Y}-\left(\mathrm{N}_{122,2 \mathrm{O}}\right)\left[\mathrm{BF}_{4}\right]$ is shown in Figure 3. A CV of HOPG in pure $\left(\mathrm{N}_{122,2 \mathrm{O} 1}\right) \mathrm{BF}_{4}$ is plotted for comparison. The $\mathrm{CV}$ profile in $\mathrm{Y}-\left(\mathrm{N}_{122,201}\right) \mathrm{BF}_{4}$ differs at potentials below $-1 \mathrm{~V}$. The current increases gradually with the lowering of potential. Three cathodic peaks (shown in Figure 3 as $a_{1}$, a $a_{2}$ and $a_{3}$ ) can be observed, respectively, at $-1.4 \mathrm{~V},-1.63 \mathrm{~V}$ and $-1.95 \mathrm{~V}$. If these peaks are related to the reduction of $\mathrm{Y}^{3+}$ to $\mathrm{Y}^{0}$, three peaks could exactly explain the three-step process of $\mathrm{Y}$ reduction, but this assumption should be confirmed by further experiments. Peak $\mathrm{b}$ is present in the $\mathrm{CV}$ of HOPG in $\mathrm{Y}-\left(\mathrm{N}_{122,201}\right) \mathrm{BF}_{4}$, but not in the CV obtained in pure $\left(\mathrm{N}_{122,201}\right) \mathrm{BF}_{4}$. It might correspond to the oxidation of low valence-state $\mathrm{Y}$. One constraint in this work was the low concentration of the $\mathrm{Y}$ precursor leading to a current of the reduction peaks that were only a little bit higher than the baseline, but less than $-10 \mu \mathrm{A}$.

For the purpose of increasing the $\mathrm{Y}$ concentration in $\left(\mathrm{N}_{122,201}\right) \mathrm{BF}_{4}$, high purity acetone (Merck, anhydrous) was used to assist the $\mathrm{Y}\left(\mathrm{NO}_{3}\right)_{3}$ dissolution analogous to (10). $383 \mathrm{mg} \mathrm{Y}\left(\mathrm{NO}_{3}\right)_{3} \cdot 6 \mathrm{H}_{2} \mathrm{O}$ were added into a mixture of $5 \mathrm{~mL}$ acetone and $5 \mathrm{~mL}$ $\left(\mathrm{N}_{122,2 \mathrm{O})}\right) \mathrm{BF}_{4}$, and kept at $60{ }^{\circ} \mathrm{C}$ for $2 \mathrm{~h}$ until all solids dissolved completely into the solvent. The solution was then heated to $110^{\circ} \mathrm{C}$ in $\mathrm{Ar}$ atmosphere for $72 \mathrm{~h}$ in order to remove the acetone. After the heating treatment, the solution separated to two different phases: a precipitation occurred at the bottom and an orange solution had been formed above. This solution was used for Y deposition experiments.

EQCM was used to study the mass change connected to the redox peaks. From the frequency change, the difference between the resonance frequency during the electrochemical measurement and the initial frequency recorded before the measurement, the mass change at the electrode surface can be calculated from the Sauerbrey equation (20), as long as the changes in the resonance frequency significantly exceed the changes in the damping (21). Figure 4 shows the EQCM results during the CV measurement in the potential range of $0 \mathrm{~V}$ to $-2.6 \mathrm{~V}$ at a scan rate of $5 \mathrm{mVs}^{-1}$. One clear cathodic peak at ca. $-2.25 \mathrm{~V}$ and its correlated anodic peak at ca. $-2.15 \mathrm{~V}$ are present in the $\mathrm{CV}$ (black line). Besides these peaks, two smaller cathodic peaks can also be observed at more positive potentials. Therefore, similar to HOPG, three cathodic peaks are visible in total. 


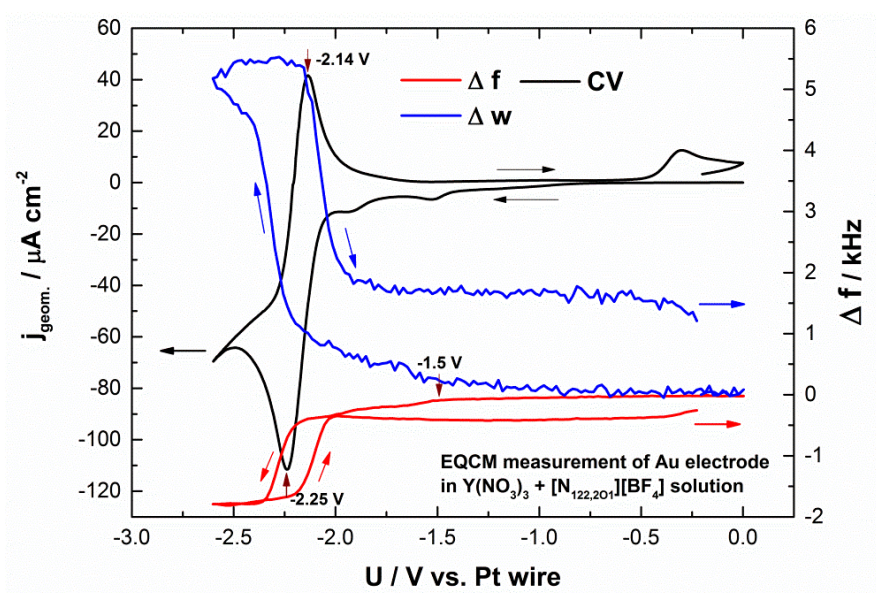

Figure 4. EQCM measurement at a gold-coated quartz crystal resonator as working electrode in a $\mathrm{Y}\left(\mathrm{NO}_{3}\right)_{3}+\left(\mathrm{N}_{122,2 \mathrm{O} 1}\right) \mathrm{BF}_{4}$ solution. The $\mathrm{CV}$, the resonance frequency change (lower curve, right axis) and damping change (upper curve, right axis) were recorded in parallel. The scan rate of the $\mathrm{CV}$ is $5 \mathrm{mV} \mathrm{s}^{-1}$.

In the cathodic scan, the resonance frequency of the quartz crystal started to decrease at the $1^{\text {st }}$ cathodic peak at ca. $-1.5 \mathrm{~V}$. The change of the frequency showed a direct correlation with the current change in the $\mathrm{CV}$. When the potential was lower than $-2.1 \mathrm{~V}$, the cathodic current density increased rapidly to a maximum of $-110 \mu \mathrm{Acm}^{-2}$, and the resonance frequency was lowered nearly by $1.75 \mathrm{kHz}$. At the same time, the damping increased by $5 \mathrm{kHz}$. When the potential was scanned anodically, an anodic peak could be observed at ca. $-2.14 \mathrm{~V}$. The resonance frequency started to increase at ca. $-2.25 \mathrm{~V}$ to a frequency which was equal to the value observed after the two small cathodic peaks in the cathodic scan, and then remained nearly constant, not reaching the original value before the experiment. In parallel, the damping decreased to a constant value as well, still larger than before the experiment. In the analysis of EQCM data, the two small peaks in the cathodic scan might be related to the adsorption of solvent or precursor ions. The coupled peaks at a potential lower than $-2.0 \mathrm{~V}$ could be the redox pair related to partially, or completely, reduced Y. Unfortunately, a translation of the change in resonance frequency into a mass change is not possible: An increase in damping normally causes a change in resonance frequency as well. In our measurement the changes in damping are roughly twice as large (actually even larger) than those of the resonance frequency. Thus it is much more probable that this frequency change is correlated to a change of electrolyte viscosity at the interface and caused by a damping change rather than to a metal deposition. However, this change is clearly related to the prominent redox processes visible in the voltammogram. Therefore, these data do not permit a clear statement about possible deposition of Y metal.

\section{Attempts of Pt-Y codeposition}

Based on the understanding of single $\mathrm{Pt}$ and $\mathrm{Y}$ deposition in $\left(\mathrm{N}_{122,2 \mathrm{O})}\right) \mathrm{BF}_{4}$, first attempts for the Pt-Y codeposition were carried out in the same ionic liquid for the purpose of $\mathrm{Pt}_{\mathrm{X}} \mathrm{Y}$ alloy preparation. The precursor was prepared by mixing the saturated $\mathrm{Pt}-\left(\mathrm{N}_{122,201}\right) \mathrm{BF}_{4}$ and saturated $\mathrm{Y}-\left(\mathrm{N}_{122,201}\right) \mathrm{BF}_{4}$ at a volume ratio of 1:1. Both voltammetric and potential step procedures were applied. However, no alloy formation was observed, and even no Pt formation was seen. 
$\underline{\text { La electrodeposition from ionic liquids }}$

Lanthanum electrodeposition was studied in both ILs using $\mathrm{La}\left(\mathrm{NO}_{3}\right)_{3}$ as precursor, motivated by the literature (10). However, the solubility of this salt was very low. At higher concentrations, the solution obtained was wax-like after heating the electrolyte to $105{ }^{\circ} \mathrm{C}$ in order to accelerate dissolution and to remove additional water from the precursor, and cooling down again. In a second approach therefore the deposition of lanthanum from a $\mathrm{La}(\mathrm{TFSI})_{3}$ precursor supplied by Solvionic was investigated. This approach appeared promising, as there is no additional anion introduced into the electrolyte, there is no problem with water contamination, and good solubility was expected. The reactions were studied with EQCM, from an $0.1 \mathrm{M} \mathrm{La(TFSI})_{3}$ solution and with $\mathrm{Au}$ as a substrate. A series of voltammetric measurements was carried out, and the lower potential limit was lowered stepwise in order to derive from the frequency shift whether deposition was taking place. Finally, an electrodeposition experiment at $-3.65 \mathrm{~V}$ was attempted, with a deposition time of $1 \mathrm{~h}$. The result is shown in Figure 5: After an initial current increase a rapid current decrease sets in. For a short time, the current appears to settle, causing a shoulder in the current trace, then it rapidly decreases, until a small rather constant current plateau is reached. Frequency and damping change again are both large, but this time their change is in the same direction, and the absolute magnitudes are comparable. This is a strong indication for an actual deposition process taking place. Therefore it is believed, that La deposition and electrolyte decomposition are taking place in parallel. A shoulder is also seen in the frequency data, but slightly later, and a maximum is seen in the damping curve, both at a time where the rate of current decrease is close to maximum.

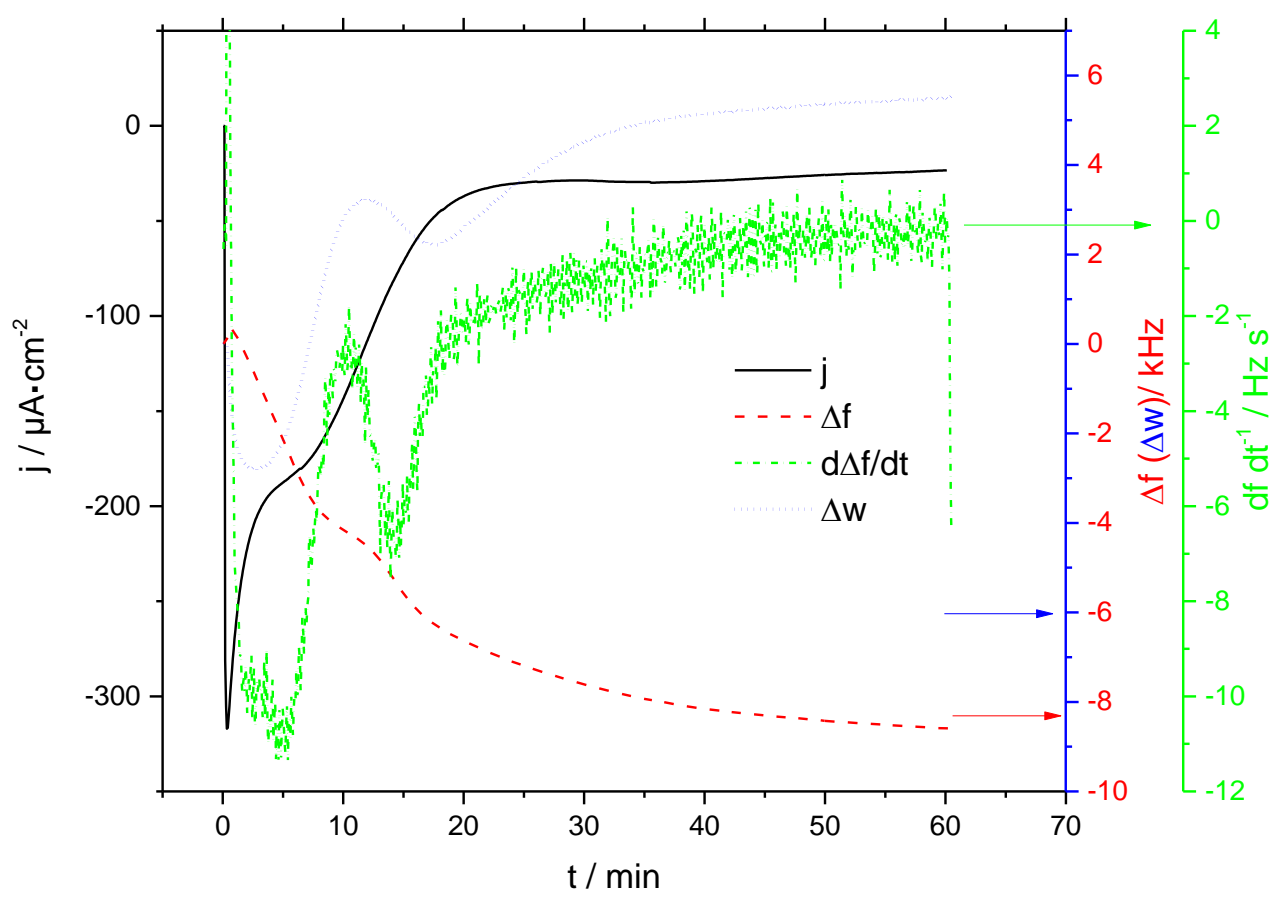

Figure 5. Potentiostatic electrodeposition experiment in in $0.1 \mathrm{M} \mathrm{La}(\mathrm{TFSI})_{3}$ in (OcMePy)TFSI at $-3.65 \mathrm{~V}$ vs. a Pt quasi-reference electrode. Current transient (line), frequency change (dashed line), damping change (dotted line) and the first derivative of the frequency change are shown. 


\section{Conclusions}

Electrodeposition of platinum, yttrium and lanthanum was studied from two room temperature ionic liquids, with the ultimate aim of developing a deposition procedure for Pt-rare earth alloy based fuel cell catalysts. The electrodeposition of Pt occurred, as reported in literature (18), via a two-step mechanism. The overpotentials required for $\mathrm{Pt}$ deposition thus are quite large, which is beneficial for alloy deposition. The electrodeposition of $\mathrm{Y}$ was not yet accomplished. In (OcMePy)TFSI a passivation reaction occurred. In this case, a disproportionation reaction similar as reported in

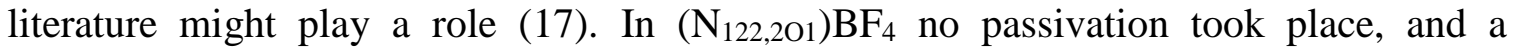
reversible redox couple was visible in the voltammogram. In-situ EQCM showed that the redox reaction taking place affects the properties of the interfacial layer in the ionic liquid as both damping and resonance frequency of the quartz change in a manner indicative of a change in viscoelastic properties. Clear indication for a metal deposition, however, was not obtained. This was different for lanthanum, where the EQCM data pointed towards a slow electrodeposition process. The rather low rate of electrodeposition using the TFSI precursor and the large overpotentials required might be related to the interfacial structure in this ionic liquid. It has been shown recently that in ionic liquids very strong interfacial layers can form that hinder electroactive ions to approach the electrode closely enough for rapid reduction $(22,23)$. Additives might disturb the interfacial structure and enable the reaction (22). Therefore further experiments on La deposition using different additive ions shall be carried out in order to accelerate the deposition. Another important parameter to be considered in future work is the temperature. Working at elevated temperatures might enhance the reaction rates. Based on the kinetic data of the individual systems then conditions for alloy deposition can be determined.

\section{Acknowledgements}

The research leading to these results has received funding from the European Union's Seventh Framework Programme (FP7/2007-2013) for the Fuel Cells and Hydrogen Joint Technology Initiative under grant agreement no. [303492], which is gratefully acknowledged. The authors thank Prof. H. Fritze (TU Clausthal) for the software for EQCM data fitting.

\section{References}

1. Y. Nonobe, M. Nada, N. Watanabe, K. Umayahara, Y. Naganuma and T. Hasegawa, Toyota Tech. Rev., 61, 15 (2015).

2. I. E. L. Stephens, A. S. Bondarenko, U. Gronbjerg, J. Rossmeisl and I. Chorkendorff, Energy Environ. Sci., 5, 6744 (2012).

3. J. K. Norskov, J. Rossmeisl, A. Logadottir, L. Lindqvist, J. R. Kitchin, T. Bligaard and H. Jonsson, J. Phys. Chem. B, 108, 17886 (2004).

4. A. U. Nilekar and M. Mavrikakis, Surf. Sci., 602, L89 (2008).

5. H. A. Gasteiger, S. S. Kocha, B. Sompalli and F. T. Wagner, Appl. Catal. B, 56, 9 (2005).

6. P. Malacrida, M. Escudero-Escribano, A. Verdaguer-Casadevall, I.E.L. Stephens and I. Chorkendorff, J. Mater. Chem. A, 2, 4234 (2014). 
7. M. Escudero-Escribano, P. Malacrida, M.H. Hansen, U.G. Vej-Hansen, A. Velázquez-Palenzuela, V. Tripkovic, J. Schiøtz, J. Rossmeisl, I.E.L. Stephens and I. Chorkendorff, Science, 352, 73 (2016).

8. P. Hernandez-Fernandez, F. Masini, D.N. McCarthy, C.E. Strebel, D. Friebel, D. Deiana, P. Malacrida, A. Nierhoff, A. Bodin, A.M. Wise, J.H. Nielsen, T.W. Hansen, A. Nilsson, I. E. L. Stephens and I. Chorkendorff, Nat. Chem., 6, 732 (2014).

9. Electrodeposition from Ionic Liquids, F. Endres, D. MacFarlane and A. Abbott, Editors, Wiley-VCH Verlag GmbH \& Co. KGaA, Weinheim (2008).

10. S. Legeai, S. Diliberto, N. Stein, C. Boulanger, J. Estager, N. Papaiconomou and M. Draye, Electrochem. Commun., 10, 1661 (2008).

11. I. Bhatt, I. May, V. A. Volkovich, D. Collison, M. Helliwell, I. B. Polovov and R. G. Lewin, Inorg. Chem., 44, 4934 (2005).

12. A. I. Bhatt, I. May, V. A. Volkovich, M. E. Hetherington, B. Lewin, R. C. Thied and N. Ertok, J. Chem. Soc., Dalton Trans., 4532 (2002).

13. Q. B. Zhang, C. Yang, Y. X. Hua, Y. Li and P. Dong, Phys. Chem. Chem. Phys., 17, 4701 (2015).

14. A. Ispas, M. Buschbeck, S. Pitula, A. Mudring, M. Uhlemann, A. Bund and F. Endres, ECS Trans., 16(45), 119 (2009).

15. L. M. Glukhov, A. A. Greish and L. M. Kustov, Russ. J. Phys. Chem. A, 84, 104 (2010).

16. M. Ishii, M. Matsumiya and S. Kawakami, ECS Trans., 50(11), 549 (2013).

17. L.-H. Chou and C. L. Hussey, Inorg. Chem., 53, 5750 (2014).

18. D. Zhang, W. C. Chang, T. Okajima and T. Ohsaka, Langmuir, 27, 14662 (2011).

19. P. He, H. Liu, Z. Li and J. Li, J. Electrochem. Soc., 152, E146 (2005).

20. G. Sauerbrey, Z. Phys., 155, 206 (1959).

21. H.L. Bandey, A.R. Hillman, M.J. Brown and S.J. Martin, Farad. Discuss., 107, 105 (1997).

22. R. Hayes, N. Borisenko, B. Corr, G.B. Webber, F. Endres and R. Atkin, Chem. Commun., 48, 10246 (2012).

23. R. Atkin, N. Borisenko, M. Druschler, F. Endres, R. Hayes, B. Huber and B. Roling, J. Mol. Liq., 192, 44 (2014). 